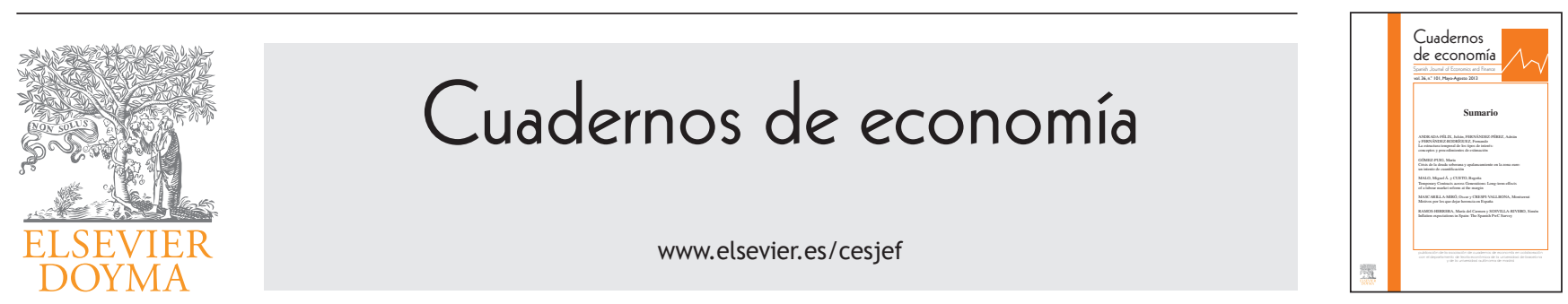

ARTÍCULO

\title{
Inflation expectations in Spain: The Spanish PwC Survey
}

\author{
María del Carmen Ramos-Herrera*, Simón Sosvilla-Rivero
}

Departamento de Economía Cuantitativa, Facultad de Ciencias Económicas y Empresariales, Universidad Complutense de Madrid, Somosaguas, Madrid, Spain

Received January 19, 2013; accepted May 27, 2013

JEL CLASSIFICATION
E31;
D84;
C33
KEYWORDS
Inflation;
Forecasting;
Expectations;
Panel data;
Econometric models

CÓDIGOS JEL

E31;

D84;

C33

\section{PALABRAS CLAVE}

Inflación;

Predicción;

Expectativas;

\begin{abstract}
We examine the predictive ability, the consistency properties, and the possible driving forces of inflation expectations, using a survey conducted in Spain by PwC, among a panel of experts and entrepreneurs. When analysing the headline inflation rate, our results suggest that the PwC panel has some forecasting ability for time horizons from 3 to 9 months, improving when it comes to predicting the core inflation rate. Nevertheless, the results indicate that predictions made by survey participants are neither unbiased nor efficient predictors of future inflation rates, regardless of the measures of inflation used. As for the consistency properties of the inflation expectations formation process, we find that panel members form stabilising expectations in the case of the headline inflation rate, both in the short and in the long-run, although in the case of the core inflation rate, consistency remains indeterminate. Finally, we find that inflation expectations are very persistent and that they appear to incorporate the information content of some macroeconomic variables (current core inflation and growth rate, the USD/EUR exchange rate, the European Central Bank (ECB) inflation target, and changes in the ECB official short-term interest rate).
\end{abstract}

๔ 2013 Asociación Cuadernos de Economía. Published by Elsevier España, S.L. All rights reserved.

\section{Expectativas de inflación en España: la encuesta PwC española}

Resumen Examinamos la capacidad predictiva, las propiedades de consistencia de las expectativas de inflación y sus posibles determinantes usando una encuesta a un panel de expertos y empresarios realizada en España por PwC. Al analizar la tasa de inflación general, nuestros resultados sugieren que el panel de PwC presenta alguna capacidad predictiva para los horizontes temporales desde 3 a 9 meses, mejorando cuando se trata de predecir la tasa de inflación subyacente. Sin embargo, los resultados indican que las predicciones realizadas por los participantes de la encuesta no son predictores insesgados ni eficientes de las tasas de inflación futuras, con independencia de las medidas de inflación empleadas. En cuanto a las propiedades

\footnotetext{
${ }^{*}$ Corresponding author.

E-mail address: madelram@ccee.ucm.es (M.C. Ramos-Herrera).
} 
Datos de panel; Modelos econométricos de la consistencia del proceso de formación de las expectativas de la tasa de inflación general, obtenemos que los panelistas forman sus expectativas de forma estabilizadoras, tanto en el corto como en el largo plazo. Al centrarse en la tasa de inflación subyacente, la consistencia queda indeterminada. Por último, obtenemos que las expectativas de inflación son muy persistentes y que parecen incorporar la información contenida en algunas variables macroeconómicas (las tasas actuales de inflación subyacente y de crecimiento real, el tipo de cambio USD/EUR, el objetivo de inflación del BCE y los cambios en el tipo de interés a corto plazo del BCE).

(c) 2013 Asociación Cuadernos de Economía. Publicado por Elsevier España, S.L. Todos los derechos reservados.

\section{Introduction}

Inflation expectations are at the centre of modern macroeconomic theory and monetary policy (see, e. g., Gali, 2008, and Sims, 2009). Virtually all macro-economic models are built on the assumption that agents maximize expected utility under a well defined distribution representing their inflation beliefs. In addition, inflation expectations are used by central banks to gain an insight into the private sector's assessment of the outlook for future inflation and to evaluate perceptions on the credibility of monetary policy. ${ }^{1}$

Despite the prominence and the ample use of expectations, the evidence about how people form their expectations and why they disagree is very scarce. The basic problem of the expectations approach to forecasting is how to uncover market participants' expectations, since this variable is in fact latent (it cannot be directly observed). Existing measurements of inflation expectations may be partitioned into two broad categories depending on whether they are direct or indirect. Indirect measurements are inferred from either financial instruments (such as the Treasury Inflation-Protected Security), the term structure of interest rates, or past realizations of inflations rates. Direct methods of measuring expectations typically rely on some sort of survey in which certain subsamples of the population are asked to reveal their personal expectations.

Empirical studies often show that inflation forecasts of professional economists influence expectations of those agents who are not experienced in macroeconomic forecasts (e.g. Carroll, 2003; Döepke et al., 2008). Although the rationality of survey forecasts has been debated (Croushore, 1998), they are generally well regarded, especially the forecasts made by the professionals. Indeed, there is some empirical evidence suggesting that median responses generally track official estimates of realized inflation, sometimes even outperforming professional forecasters (see, Hafer \& Hein, 1985; Thomas, 1999, and Ang et al., 2007, among others). Ang et al. (2007) argue that the superior performance of survey forecasts could be related to the fact that the surveys simply aggregate information from many different sources, not captured by a single model.

1. Bernanke et al. (2001) discuss how the behaviour of survey forecasts relative to the central bank's inflation target provides information on credibility.
In this paper, we examine the predictive ability and consistency of expectations on the inflation rate based on the quarterly survey conducted by the Spanish branch of PricewaterhouseCoopers ( $\mathrm{PwC}$ ), as well as the possible driving forces behind the expectation formation process. Our sample consists of thirty surveys covering the period from 2003:II to 2011:III.

We consider that the theme of our paper is of interest in two aspects: from the economic agents' perspectives, where inflation expectations are relevant in decision making, looking for maximise expected utility, and from the side of the study of communication strategies of central banks, inflation forecast targeting, and their credibility (see, e. g. Mishkin, 2006).

Regarding this second aspect, a relevant feature of modern central banks is the change in communication strategies (Bûlir et al., 2008). Market participants use interest rate decisions as well as communication of the central bank to infer the future path of monetary policy. Studies like those of Ehrmann and Fratzscher (2007, 2009) and Lamla and Lein (2011) explore the importance of central bank communication relative to the announced interest rate decision for guiding money markets. While monitoring market interest rates, they find that the information provided by the press conference is very relevant. Conrad and Lamla (2010) and Hayo and Neuenkirch (2012) found effects of central bank communication on other markets like bonds, stocks and foreign exchange rates.

The paper is organised as follows. Section 2 describes the data. In Section 3 the forecast accuracy of the survey is assessed. Section 4 examines the consistency properties of the inflation rate expectation formation process of short and long forecasts. In Section 5 we explore the role of potential determining factors in explaining the expectation formation process revealed by the panel. Finally, in Section 6 some concluding remarks are offered.

\section{The survey data}

Since 1999, the Spanish branch of PwC has been conducting a quarterly survey on the Spanish economic situation. One of the questions refers to inflation rate expectations. Survey participants are asked in the last week prior to quarter's end to deliver three and nine- month-ahead expectations, or six and twelve- month-ahead expectations of the inflation rate. The dates when the surveys were conducted have been recorded. We have included in the data set the 
Table 1 Forecast accuracy

\begin{tabular}{|c|c|c|c|c|c|}
\hline & RMSE & $\begin{array}{l}\text { Theil inequality } \\
\text { coefficient }\end{array}$ & $\begin{array}{c}\text { Bias } \\
\text { proportion }\end{array}$ & $\begin{array}{l}\text { Variance } \\
\text { proportion }\end{array}$ & $\begin{array}{l}\text { Covariance } \\
\text { proportion }\end{array}$ \\
\hline \multicolumn{6}{|c|}{ Panel A: Headline inflation } \\
\hline 3-month ahead & 0.972937 & 0.166897 & 0.004262 & 0.063673 & 0.932064 \\
\hline 6-month ahead & 1.054963 & 0.197166 & 0.063899 & 0.011847 & 0.924255 \\
\hline 9-month ahead & 1.579039 & 0.290485 & 0.023790 & 0.141639 & 0.834571 \\
\hline 12-month ahead & 1.703497 & 0.310188 & 0.045373 & 0.089201 & 0.865427 \\
\hline \multicolumn{6}{|c|}{ Panel B: Core inflation } \\
\hline 3-month ahead & 0.565846 & 0.117376 & 0.015627 & 0.000036 & 0.984336 \\
\hline 6-month ahead & 0.538645 & 0.118828 & 0.016251 & 0.000012 & 0.983737 \\
\hline 9-month ahead & 0.830764 & 0.183802 & 0.005659 & 0.098943 & 0.895398 \\
\hline 12-month ahead & 0.903056 & 0.201881 & 0.017680 & 0.048886 & 0.933434 \\
\hline
\end{tabular}

RMSE, root mean square error.

observed, 3-, 6-, 9-, and 12-month ahead inflation rates computing from the overall Consumer Price Index (CPI), taking from the National Statistics Institute (Instituto Nacional de Estadística (INE)).

The PwC survey is based upon the opinion of panels of experts and entrepreneurs. The panel members cover the following sectors: non-financial corporations (an average of $32.22 \%$ of respondents), universities and economic research centres $(24.26 \%)$, financial system $(21.48 \%)$, business and professional associations (17.31\%) and institutions $(4.65 \%)$. The number of participants of the survey varies from 95 in the third quarter of 2009 to 156 in the fourth quarter of 2004, with 118 being the average number of participants.

One important feature of the Spanish PwC panel is the anonymity of forecasters. Although the names of the panel participants are provided for each survey, it is not possible to know the answers of each person, so the researcher cannot follow the forecasts of a particular panel member over time. Nevertheless, this anonymity could encourage people to provide their best forecasts, without fearing the consequences of making forecast errors.

We concentrate on the 3-, 6-, 9- and 12-month ahead forecasts, using 30 of the 33 surveys available. ${ }^{2}$ On average, the number of survey participants who responded to our question of interest was 115 , reaching its minimum value of 90 people in 2009:III and its maximum value of 154 people in 2004: IV.

\section{Forecast accuracy}

We initially evaluated the forecasting performance of the PwC panel in explaining headline inflation using the root mean square error (RMSE) and the Theil inequality coefficient. Additionally, we also consider the decomposition of the mean squared forecast error in its bias, variance and covariance proportions in order to assess, respectively, how

2. We do not have enough information for the question of the inflation rate for the surveys corresponding to the third quarter of 2007, the first quarter of 2008 and finally the third quarter of 2010. far the mean of the forecast is from the mean of the actual series, how far the variation of the forecast is from the variation of the actual series, and how large is the remaining unsystematic forecasting errors.

Panel A in Table 1 shows the forecasting performance of our panel in tracking evolution of the overall CPI for 3-, 6-, 9- and 12-month ahead. As can be seen, the RMSE is large and increases with the forecast horizon, which means that forecasters have made mistakes in their predictions and make it worse as we move away from the temporal horizon. This finding is reinforced using the Theil inequality coefficient, since it is not close to zero. This result could be related to the following theoretical explanation on the longer time horizon, the closer the forecast to the target. Indeed, even when the European Central Bank and the central banks of the member states that belong to the eurozone are not considered explicit inflation targeters, they have set the primary objective of maintaining price stability, defined as inflation rates below, but close to, $2 \%$ over the medium term. It has been noted that a central bank operating within explicit inflation targets, sets monetary policy instruments, as such that the expected value of inflation equals the inflation target (in this case below, but close to $2 \%$ ). This depends on the information that economic agents have regarding central bank actions. If agents have complete information about the strategy of monetary policy applied by the central bank, they will expect an inflation level close to the inflation target. In this case, agents will not make systematic forecast errors (Capistran \& RamosFrancia, 2010). In this sense, if the central bank is credible, medium-term inflation expectations (two years ahead) should be anchored to the target or nearby. That is, the longer the inflation forecasts time horizon (closer to medium-term), the closer the inflation expectations to the target. Medium-term expectations will depend less on cyclical economic factors and more on the central bank credibility.

As for the bias proportion, since it is always zero, it suggests no systematic error in the forecasts of the PwC panel. The estimated variance proportion indicates a notable ability of the forecasts to replicate the degree of variability in the inflation rate, at least for the horizons $k=3$ and 6 . For these forecasting horizons, the bias and 
variance proportions are small, so that most of the bias is concentrated on the covariance proportions (i.e., in the unsystematic error). In other words, the mistakes made by panel members are not deterministic, in particular, the deviation of inflation rate prediction with respect to the actual value is random.

In economic applications the forecast user is often interested in directional (up/downward) movements of the variable under analysis. To assess if the PwC panel is able to predict more accurately than a random walk direction of headline inflation movements, we have also computed the percentage of correct predictions. As can be seen in Panel A of Table 2, panel participants correctly forecast the change of the inflation rate in $58.82 \%$ of the cases for $\mathrm{k}=3$ and 9 and in $61.54 \%$ of the cases for $\mathrm{k}=6,12$. Therefore, panel forecasts are clearly outperforming the random walk directional forecasts in all horizons.

Therefore, the evidence presented in Panels $\mathrm{A}$ of Tables 1 and 2 suggests that the PwC panel has some forecasting ability in tracking the evolution of the headline inflation in Spain, at least until 9-months ahead.

Blinder and Reis (2005) argue that it is better to predict headline inflation using lagged core (rather than headline) inflation. To explore the possibility that the participants in the PwC panel could be paying less attention to headline inflation data, but still be relying heavily on core inflation data, we have assessed the forecast accuracy and the

Table 2 Directional forecast

\begin{tabular}{cc}
\hline Panel A: Headline inflation & \\
3-month ahead & 58.82 \\
6-month ahead & 61.54 \\
9-month ahead & 58.82 \\
12-month ahead & 61.54 \\
Panel B: Core inflation & \\
3-month ahead & 82.35 \\
6-month ahead & 76.92 \\
9-month ahead & 76.47 \\
12-month ahead & 76.92 \\
\hline
\end{tabular}

directional forecast behaviour of the inflation expectations when forecasting core inflation. Panel B in Tables 1 and 2 show the results.

As can be seen, there is a general improvement in both the RMSE statistic, the Theil inequality coefficient, and in the directional forecasts. Surprisingly, forecasts of headline inflation are rather good forecasts of core inflation. Therefore, our results seem to suggest that the panel participants may be implicitly forecasting the core inflation rate, instead of the headline inflation rate (which is what they are asked to forecast).

As a further assessment of the accuracy of the forecasts made by the PwC panel, we tested the hypothesis that the panel forecasts are optimal predictors of future inflation rates. If the forecasts made by panel participants are unbiased and efficient predictors of the future inflation rate, a regression of the observed inflation rate at time $t+k$ $\left(\pi_{t+k}\right)$ on the expected rate determined at time $t$ for $k$-periods ahead $\left(\pi_{t+k}^{e}\right)$.

$\pi_{t+k}=\alpha+\beta \pi_{t+k}^{e}+\varepsilon_{t+k}$

should result in an estimated constant $(\hat{\alpha})$ not significantly different from zero, and an estimated coefficient on the expected rate $(\hat{\beta})$ not significantly different from one. Table 3 presents the estimation results and the Wald test on the joint hypothesis: $H_{0}: \hat{\alpha}=0, \hat{\beta}=1$. Moreover, Grant and Thomas (1999) contend that this hypothesis can be used to verify the existence of "weak form of rationality" since the rational expectations hypothesis does not require the forecasts to be strictly correct in all periods but, instead, requires the forecast errors to be unbiased and uncorrelated with any information in which the forecast is conditioned (see Clements, 2005).

As can be seen, the results suggest that we can decisively reject the null hypothesis for all forecast horizons, indicating that such forecasts are biased and not efficient predictors of the future inflation rate, regardless of the inflation measures (headline or core inflation) used as observed inflation rate. Therefore, our results support a "weak form of rationality" for the PwC panel base-inflation expectations, partially reflecting the degree of sophis-

Table 3 Forecast optimality

\begin{tabular}{lcccc}
\hline & 3-month ahead & 6-month ahead & 9-month ahead & 12-month ahead \\
\hline $\begin{array}{l}\text { Panel A: Headline inflation } \\
\hat{\alpha}\end{array}$ & $0.612682(0.0000)$ & $1.906420(0.0000)$ & $2.535416(0.0000)$ & $3.452318(0.0000)$ \\
$\hat{\beta}$ & $0.754766(0.0000)$ & $0.299054(0.0000)$ & $0.044489(0.1611)$ & $-0.258337(0.0000)$ \\
Prob(F-statistic) & 0.0000 & 0.0000 & 0.161124 & 0.0000 \\
Wald F-test & $86.34462(0.0000)$ & $744.6454(0.0000)$ & $454.0752(0.0000)$ & $700.3444(0.0000)$ \\
No. of observations & 1937 & 1504 & 1937 & 1504 \\
Panel B: Core inflation & & & & $1.030993(0.0000)$ \\
$\hat{\alpha}$ & $0.691741(0.0000)$ & $0.700064(0.0000)$ & $1.458905(0.0000)$ \\
$\hat{\beta}$ & $0.586298(0.0000)$ & $0.565421(0.0000)$ & $0.429859(0.0000)$ & $0.297322(0.0000)$ \\
Prob(F-statistic) & 0.0000 & 0.0000 & 0.0000 & 0.0000 \\
Wald F-test & $1272.243(0.0000)$ & $1104.672(0.0000)$ & $798.0567(0.0000)$ & $632.5904(0.0000)$ \\
No. of observations & 1937 & 1504 & 1937 & 1504 \\
\hline
\end{tabular}

Notes: $\mathrm{p}$-values in parenthesis. 
tication of the models and frameworks used by the Spanish market agents when forming their inflation expectations.

\section{Expectation consistency}

According to Froot and Ito (1989), consistency of expectations formed at the same point in time prevails if expectations about inflation rate changes during subsequent shorter time periods and expectations about the inflation rate for the entire time period give the same result. Note that consistency is a necessary condition if expectations are to be rational, but is weaker than rationality since it does not require that the expectation process matches the stochastic process, generating actual inflation rates.

Following Frankel and Froot (1987a, 1987b) and Frenkel et al. (2012), we assume that inflation rate forecasters build their expectations by using an extrapolative model which can, in its simplest form, be expressed as a distributed lag function with one lag:

$E_{t, i}\left(\pi_{t+k}\right)-\pi_{t}=\alpha_{k}+\beta_{k}\left(\pi_{t-1}-\pi_{t}\right)+\varepsilon_{t, i}$

where $\pi_{t}$ and $E_{t, i}\left(\pi_{t+k}\right)$ denote, respectively, the inflation rate at time $t$ and the expected inflation rate for time $t+k$ made by forecaster $i$ at time $t$. Subscript $k$ denotes the forecast horizon and $\varepsilon$ the error term.

A positive $\beta_{k}$ indicates that with a slowdown in price growth during the period preceding the time of the forecast leads panel members to expect an opposite effect for the next period. Therefore, they will expect that the inflation rate in $t+k$ exceeds $t$, expectations being in this case stabilising. On the contrary, if $\beta_{k}$ is negative, and in the preceding period forecasters observe that the rate at which prices grow is less, then they expect that the inflation rate in $t+k$ is less than $t$, expectations being in this case destabilising.

Note that in our survey data gathers the participants' expectations at different horizons at the same point of time, the information set available to the agent being the same, therefore allowing us to formally estimate (2) for such forecasting horizons. Table 4 reports the results. As can be seen in Panel $A$, the short-run $\beta_{k}$ and the long-run $\beta_{k}$ are positive for both time horizons ( 3 and 9 months and 6 and
12 months), indicating that survey participants form stabilising expectations in the short-run and in the long-run when forecasting headline inflation. This result suggests that we should not reject the null hypothesis that short-run forecasts are consistent with long-run forecasts. As for the forecasting of core inflation, results in Panel B. In this case, the estimated betas do not coincide in sign, either in the short or in the long term. Regarding the long term, on the one hand, facing a reduction in the core inflation rate, the PwC panel expects a higher core inflation rate nine months later compared with the current rate (since the estimated beta is positive). On the other hand, if the panel participants observe that the core inflation rate in the month of the survey is lower than that in the previous month, they predict that this reduction will be further strengthened after twelve months, being therefore, destabilising expectations. While consistency is indeterminate in the long run, the situation does not change when we focus on the short term. The reason is that when facing a reduction in the inflation rate, the PwC panel forms destabilising expectations and, although the estimated beta for $\mathrm{k}=3$ also appears with a negative sign, it is not statistically significant and, after taking the constant out of the regression, the estimated beta experiences a change of sign, implying stabilising expectations.

\section{Determining factors of the inflation expectations}

To shed further light on the expectation formation process, in this section we explore the role of some variables as driving factors behind the inflation expectations declared by the PwC panel. In particular, we assessed the significance of the following potential determing factors: the inflation target of the European Central Bank (ECB) (proxied as 2\%), nominal exchange rate (USD/EUR), real growth (proxied by the growth rate of the industrial production index), core inflation rate, changes in the ECB official interest rate and lagged inflation expectations. Note that information regarding these variables is always available at the time the expectations are formed.

$\pi_{t+k}^{e}=\pi_{\text {target }, t}+\alpha_{1} S_{t}+\alpha_{2} \rho_{t}+\alpha_{3} \pi_{\text {core }, t}+\alpha_{4} \Delta_{i}+\alpha_{5} \pi_{t+k-1}^{e}+\varepsilon_{t+k}$

Table 4 Expectation formation processes

\begin{tabular}{lcccc}
\hline & 3-month ahead & 6-month ahead & 9-month ahead & 12-month ahead \\
\hline Panel A: Headline inflation & & & & \\
$\hat{\alpha}$ & $-0.143692(0.0000)$ & $-0.193739(0.0000)$ & $-0.157764(0.0000)$ & $-0.250228(0.0000)$ \\
$\hat{\beta}$ & $0.919159(0.0000)$ & $0.758780(0.0000)$ & $0.946908(0.0000)$ & $1.325477(0.0000)$ \\
Prob(F-statistic) & 0.0000 & 0.0000 & 0.0000 & 1500 \\
No. of observations & 1937 & 1937 & 1504 & 0.0000 \\
Panel B: Core inflation & & & $0.422821(0.0000)$ & $0.326668(0.0000)$ \\
$\hat{\alpha}$ & $0.358212(0.0000)$ & $0.274911(0.0000)$ & $-0.197418(0.0376)$ \\
$\hat{\beta}$ & $-0.062959(0.4079)$ & $0.392143(0.0000)$ & $-0.673636(0.0000)$ & -0.0000 \\
Prob(F-statistic) & 0.407949 & 0.0000 & 0.0000 & 1504 \\
No. of observations & 1937 & 1937 & & 1504 \\
\hline
\end{tabular}

Notes: $\mathrm{p}$-values in parenthesis. 
Table 5 Determinants of the inflation expectations

\begin{tabular}{lrrrr}
\hline & 3-month ahead & 6-month ahead & 9-month ahead & 12-month ahead \\
\hline ECB Inflation Target & $-0.141659(0.0005)$ & $-0.295901(0.0000)$ & $-0.132021(0.0023)$ & $-0.222871(0.0000)$ \\
Nominal Exchange Rate & $0.243537(0.0001)$ & $0.516912(0.0000)$ & $0.270501(0.0000)$ & $0.442695(0.0000)$ \\
Real Growth & $0.004353(0.0000)$ & $0.007969(0.0000)$ & $0.004332(0.0000)$ & $0.005687(0.0000)$ \\
Core Inflation Rate & $0.069069(0.0000)$ & $0.108148(0.0000)$ & $0.073107(0.0000)$ & $0.097373(0.0000)$ \\
Changes in ECB Official & $-0.131426(0.0006)$ & $0.056819(0.0815)$ & $-0.113218(0.0057)$ & $0.065507(0.0542)$ \\
$\quad$ & & & & \\
$\quad$ Interest Rate & $0.929534(0.0000)$ & $0.880365(0.0000)$ & $0.904352(0.0000)$ & $0.866727(0.0000)$ \\
Lagged Inflation & 0.961531 & 0.960168 & 0.931463 & 0.936204 \\
$\quad$ Expectations & 2.033311 & 1.907787 & 2.126202 & 1.924588 \\
R-squared & 1936 & 1503 & 1936 & 1503 \\
Durbin-Watson stat & & & & \\
No. of observations & & &
\end{tabular}

ECB, European Central Bank.

As can be seen in Table 5, our results indicate quite a significant persistence of inflation expectations, since the estimated autoregressive coefficients are very high (ranking from 0.8667 to 0.9295$)$. In addition, expectations are positively related to the current core inflation and growth rates and the exchange rate. On the other hand, results also suggest a negative coefficient for ECB inflation target, while the coefficient for the ECB official short-term interest rate is negative for $k=3$ and 9 , and positive for $k=9$ and 12 . Therefore, the PwC panel appears to incorporate the information content of a broad set of macroeconomic variables when forming their inflation expectations.

Notice that current inflation is determined by past decision and events, so the central bank current actions by traditional channels only have effects on future inflation. Some central banks have as intermediate target the inflation forecasts (Svensson, 1997). Since the lag control for monetary policy is close to 2 years, it would be of interest to test if the results obtained with the 3, 6, 9 and 12 months replicates when using a longer time horizon (for example 2 years ahead). Although this exercise could shed some light on the credibility of the central bank actions and policy implications, it is not possible due data unavailability.

\section{Concluding remarks}

Expectations are essential for determining economic outcomes and for policymakers. Survey-based measures of inflation provide point forecasts of inflation expectations at various horizons, covering both the short and medium to longer term.

In this paper, we aim to provide a simple investigation of Spanish survey-based inflation expectations. To that end, we have investigated predictive ability and consistency properties of inflation expectations using a survey conducted in Spain by PwC among a panel of experts and entrepreneurs, offering further evidence on the explanatory power of expectations directly observed from survey data.

Our results suggest that the PWC panel has some forecasting ability for time horizons from 3 to 9 months when tracking future general inflation rates, and improving when it comes to predicting the core inflation rate. Nevertheless, the results confirm that predictions made by survey participants are neither unbiased nor efficient predictors of future inflation rates, regardless of the measurements of inflation used.

As for the consistency properties of the inflation expectations formation process, we find that panel members form stabilising expectations in the case of the headline inflation rate, both in the short and in the long-run, although in the case of the core inflation rate, consistency remains indeterminate.

When considering a set of information variables that are relevant for predicting inflation and are available at the time the expectations are formed, we find that inflation expectations are very persistent, and that they are positively related to the current core inflation and the USD/ EUR exchange rate, but negatively related to ECB inflation target, while the sign of the coefficient for the ECB official short-term interest rate depends on the forecast horizon.

\section{Funding}

Financial support by the Spanish Ministry of Science and Innovation (ECO2011-23189) is also gratefully acknowledged. María del Carmen Ramos-Herrera also acknowledges her grant (F.P.U.) from the Spanish Ministry of Science and Innovation (Ref. AP2008-004015).

\section{Acknowledgements}

The authors would like to thank two anonymous referees for helpful comments and suggestions on a previous draft of this paper, substantially improving the content and quality of the paper. The authors also wish to thank PricewaterhouseCoopers in Spain for kindly providing us with the data set.

\section{References}

Ang, A., Bekaert, G., Wei, M., 2007. Do macro variables, asset markets or surveys forecast inflation better? Journal of Monetary Economics 54, 1163-1212.

Bernanke, B., Laubach, T., Mishkin, F., Posen, A., 2001. Inflation targeting: Lessons from the international experience. Princeton University Press, Princeton, NJ. 
Blinder, A.S., Reis, R., 2005. Understanding the Greenspan standard, in the greenspan era: Lessons for the future. Economic Symposium, Federal Reserve Bank of Kansas City, 11-96.

Bûlir, A., Smidkova, K., Kotlan, V., Navratil, D., 2008. Inflation targeting and communications: It pays off to read inflation reports. IMF Working Paper WP/08/234.

Capistran, C., Ramos-Francia, M., 2010. Does Inflation targeting affect the dispersion of inflation expectations? Journal of Money, Credit and Banking 42, 113-34.

Carroll, C.D., 2003. Macroeconomic expectations of households and professional forecasters. Quarterly Journal of Economics 118, 269-298.

Clements, M.P., 2005. Evaluating econometric forecasts of economic and financial variables. Palgrave Macmillan, Houndmills, Basingstoke, Hampshire.

Conrad, C., Lamla, M.., 2010. The high-frequency response of the EUR-US dollar exchange rate to ECB monetary policy announcements. Journal of Money, Credit and Banking 72, 1391-1417.

Croushore, D., 1998. Evaluating inflation forecasts. Federal Reserve Bank of Philadelphia Working Paper No. 98-14.

Döepke, J., Dovern, J., Fritsche, U., Slacalek, J., 2008. The dynamics of European inflation expectations. The B.E. Journal of Macroeconomics 8, article 12.

Ehrmann, M., Fratzscher, M., 2007. Communication by central bank committee members: Different strategies, same effectiveness? Journal of Money, Credit and Banking 39, 509-541.

Ehrmann, M. Fratzscher, M., 2009. Explaining monetary policy in press conferences. International Journal of Central Banking 5, 42-84.

Frankel, J. A., Froot, K.A., 1987a. Using survey data to test standard propositions regarding exchange rate expectations. American Economic Review 77, 133-153.
Frankel, J. A., Froot, K.A., 1987b. Short-term and long-term expectations of the yen/dollar exchange rate: Evidence from survey data. Journal of the Japanese and International Economies 1, 249-274.

Frenkel, M., Rülke, J.C., Stadtmann, G., 2012. Twisting the dollar? On the consistency of short-run and long-run exchange rate expectations. Journal of Forecasting 31, 596-616.

Froot, K.A., Ito, T., 1989. On the consistency of the short and long run exchange rate expectations. Journal of International Money and Finance 8, 487-510.

Gali, J., 2008. Monetary policy, inflation and the business cycle: An introduction to the new keynesian framework. Princeton University Press, Princeton, NJ.

Grant, A.P., Thomas, L.B., 1999. Inflationary expectations and rationality revisited. Economics Letters 62, 331-338.

Hafer, R.W., Hein, S.E., 1985. On the accuracy of time-series, interest rate, and survey forecasts of inflation. The Journal of Business 58 , 377-398.

Hayo, B., Neuenkirch, M., 2012, Domestic or U.S. news: What drives Canadian financial markets? Economic Inquiry 50, 690-706.

Lamla, M.J., Lein, S.M., 2011. What matters when? The impact of ECB communication on financial market expectations. Applied Economics 43, 4289-4309.

Mishkin, F.S., 2006. The inflation targeting debate, Bank of Canada. In: Annual Conference. Bank of Canada, Ottawa, pp. 195-220.

Sims C., 2009. Inflation expectations, uncertainty and monetary policy. BIS Working Paper No. 275.

Svensson, L.E.O., 1997. Inflation forecast targeting: Implementing and monitoring inflation targets. European Economic Review 41, 1111-1146.

Thomas, L.B. Jr., 1999. Survey measures of expected U.S. inflation. Journal of Economic Perspectives, 13, 125-144. 